\title{
FLOSS in New Zealand Public Libraries
}

\author{
by
}

\section{Hamish Noonan}

Submitted to the School of Information Management, Victoria University of Wellington

in partial fulfilment of the requirements for the degree of Master of Information Studies 


\section{Abstract}

This study attempts to gain an understanding of the uses and potential uses of FLOSS (free/libre and open source software) in New Zealand public libraries; including how FLOSS is currently being used by New Zealand public libraries, problems encountered with FLOSS, benefits received from using FLOSS, and how libraries came to the decision to use FLOSS.

It uses an instrumental case study approach and interviews eight participants from four institutions; Te Horowhenua Trust, Auckland Libraries, Aotearoa People's Network Kaharoa and South Taranaki LibraryPlus.

The research found that participants were very happy with their FLOSS usage, and that it was important for governing bodies and IT departments to be supportive of experimentation and innovation. Benefits of FLOSS included lack of vendor lock-in, lower cost, flexibility, ability to influence the development of the software, the philosophies and ethos of FLOSS, better features, stability, community support and the ability to give patrons software to use outside the library.

Information sharing between libraries and engagement with FLOSS communities were important factors in successful use. Further research could study how software procurement decisions are made in New Zealand libraries, and whether FLOSS is being overlooked due to preconceptions or uneven decision-making processes.

Keywords: open source software, New Zealand public libraries, Koha 


\section{Table of Contents}

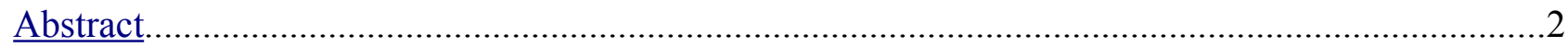

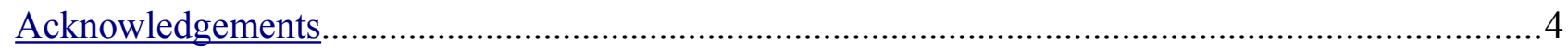

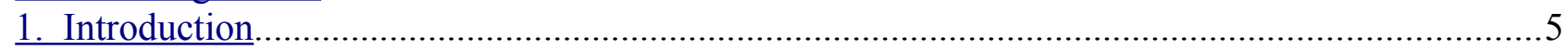

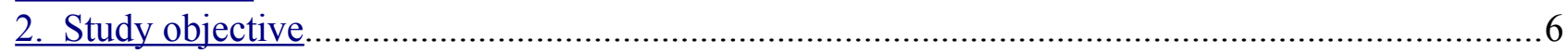

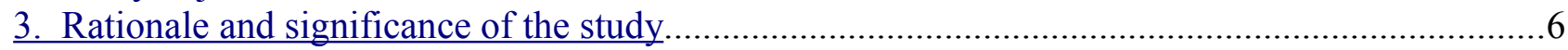

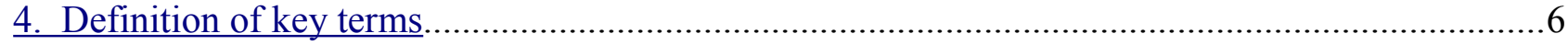

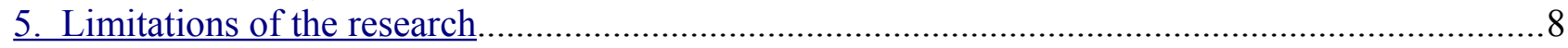

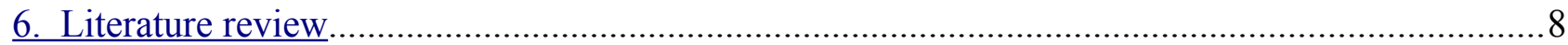

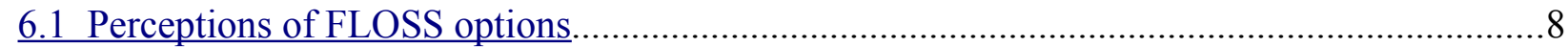

$\underline{6.2}$ The ethos of the FLOSS movement and public libraries...................................................

6.3 How FLOSS is being used in public libraries.............................................................. 10

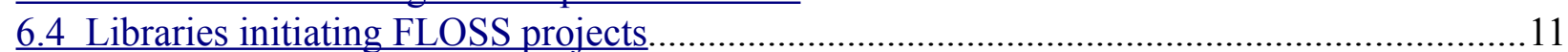

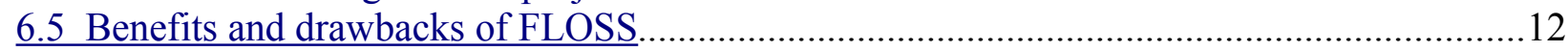

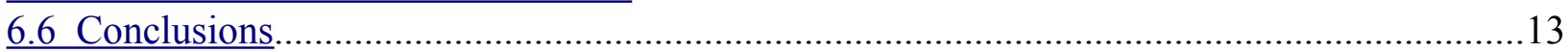

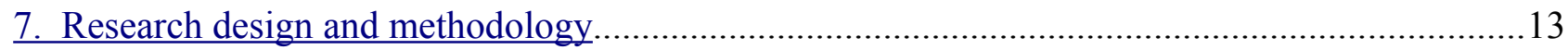

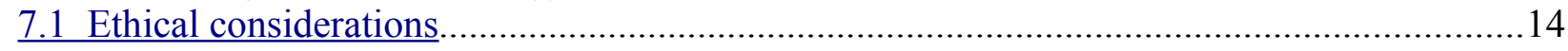

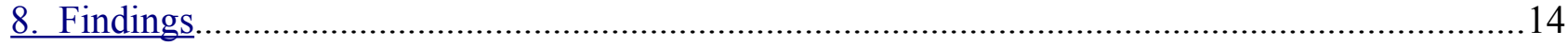

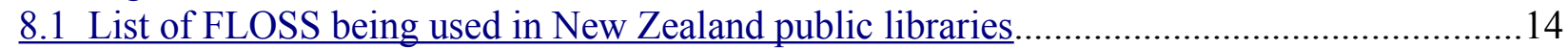

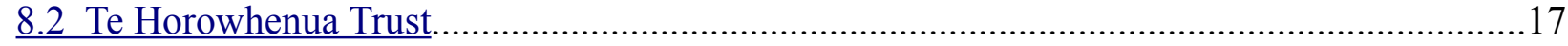

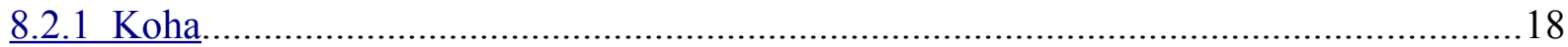

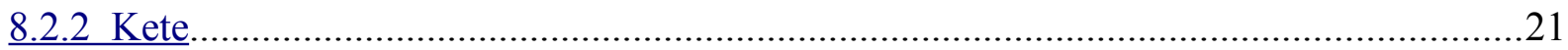

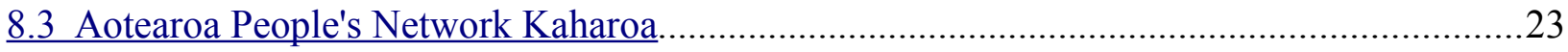

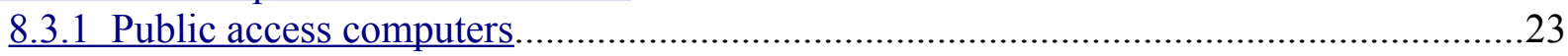

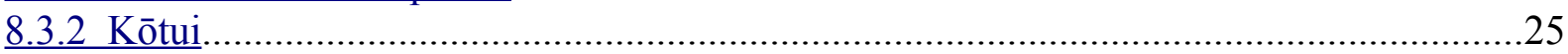

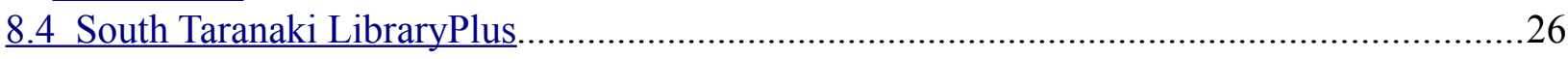

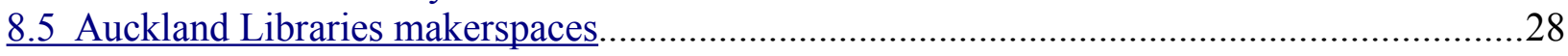

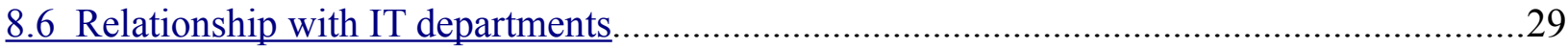

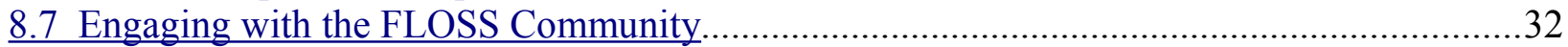

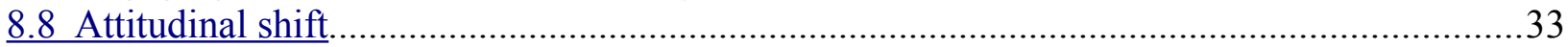

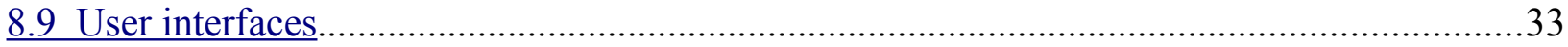

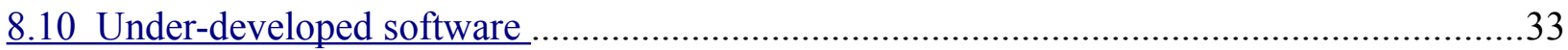

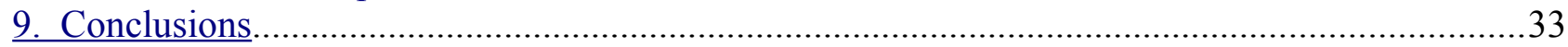

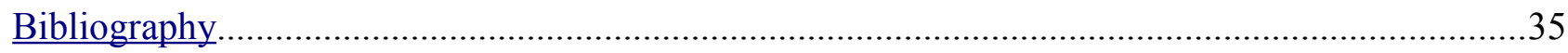




\section{Acknowledgements}

My sincere thanks to Dr Brenda Chawner, my supervisor, who helped steer this research with her expertise and enthusiasm.

Thanks also to the research participants, pubrarians and Yasmin Zabidin. 


\section{Introduction}

The world's first FLOSS (free/libre and open source software) integrated library system, Koha, was deployed in New Zealand 16 years ago (Jaffe et al., 2007, p14). FLOSS is software that can be downloaded for free with no licence costs. It also allows the user to adapt, customise, study and redistribute the software. FLOSS is usually developed in a public collaborative manner (Khode \& Chandel, 2015, p30).

Some writers have noted the natural synergy between the tradition of freely sharing information in libraries and the 'gift culture' of FLOSS projects (Chawner, 2005, p1). Both FLOSS and public libraries depend on 'community effort' for their success (Singh, 2014, p52), and have shared values of openness and accessibility (Jaffe \& Careaga, 2007, p1). Public libraries have an important role in breaking down the digital divide, by providing computer access and assistance to often partly disenfranchised members of the public. Providing FLOSS options in these formative environments can prevent patrons being locked in to proprietary software habits when they obtain their own computers.

Other benefits of FLOSS include portability, free upgrades, educational benefits, greater efficiency through anti-monopolistic behaviour (Deek \& McHugh, 2008, p3), lower environmental impact (Houser, 2009, p35), and freedom from vendor lock-in (Rafiq, 2009, p138). Drawbacks can include software maturity and a lack of technical support options (Pruett \& Choi, 2013). While FLOSS has no licensing costs, it does cost libraries in terms of support, customisation and time spent on staff training.

Despite the natural synergies there has been a low uptake of FLOSS in New Zealand libraries. There has been some excellent research in to the usage of FLOSS in public libraries such as Rafiq (2009), Albee and Chen (2014), and Singh (2013), but very little specifically in a New Zealand context. 
This report looks at how FLOSS is being used in New Zealand public libraries, including the problems and benefits encountered. It also looks at factors influencing the decision to use FLOSS.

\section{Study objective}

The objective is to gain an understanding of the uses and potential uses of FLOSS in New Zealand public libraries. The research questions to support this objective are:

In which ways is FLOSS currently being used by New Zealand public libraries?

- What problems with FLOSS have they encountered?

- What benefits of using FLOSS have they received?

- How did they come to the decision to use FLOSS?

\section{Rationale and significance of the study}

There is anecdotal evidence of library staff being refused access to FLOSS or dismissing it as an option for spurious reasons. This study will help public libraries in their decision-making processes when choosing software, and will help them make their cases to governing councils and their IT departments. It may also help librarians re-consider concepts such as interoperability and accessibility with regard to software.

\section{Definition of key terms}

FLOSS (free/libre and open source software) and FOSS (free open source software) are composite terms for software that meets the definitions of both free software and open source software. The word libre is specifically included to emphasise the concept is about freedom, rather than price (Skidmore, 2007, p395). In practice the definitions for 'open source software' and 'free software' have much the same effect (Chawner, 2004, p3). 
Free software is an older term for OSS, and is an intentionally evocative term intended to resonate with the values of freedom (Deek \& McHugh, 2008, p2). The term was coined by Richard Stallman who states it "is a matter of freedom, not price, so think of 'free speech,' not 'free beer"'(Stallman, 2010, p83). A more complete definition is provided by the Free Software Foundation (Free Software Foundation, 2013).

An integrated library system (ILS) is the primary functional system of a library. It is an automated system, which usually consists of acquisitions, circulation, cataloguing, and serials modules, and an OPAC (Online Public Access Catalogue); in which all of the modules share a common bibliographic database (Li, 2008).

A makerspace, also known as a hackerspace, is a place where people with common interests, often in computers, technology, science, digital or electronic art; can meet, socialise and collaborate (Barniskis, 2014, p6).

Open source software (OSS) is software that is distributed with human readable source code in order to allow the user freedom to modify and freely redistribute the code (Engard, 2010, p3). A more complete and specific definition is provided by the Open Source Initiative in the Open Source Definition (Open Source Initiative, 2014). The term is controversial amongst free software pioneers as it is considered a rejection of the free software movement's ethical and social values (Stallman, 2010, p83).

Proprietary software is software that has the redistribution and modification of it restricted or prohibited (Stallman, 2010, p81). This includes software that requires permission for redistribution or modification (Stallman, 2010, p81). It is often confused with commercial software as most commercial software is proprietary, but FLOSS can also be commercial (Stallman, 2010, p82).

A public library is a library open to the general public, as opposed to a specialist library or an academic library. In New Zealand public libraries are generally run by 
local body councils. In this study the definition of "public library" is limited to professionally-run council-funded libraries, because volunteer-run libraries tend to have different approaches and software needs.

\section{Limitations of the research}

This study concentrates on four institutions that were selected because they were already using FLOSS in significant ways. Therefore the results can not be extrapolated to draw conclusions on the broader usage of FLOSS in New Zealand public libraries.

\section{Literature review}

This preliminary literature review critiques journal articles with relevancy to the study objective. There is very little research about the topic in New Zealand public libraries; therefore most of the review will be about studies asking similar questions of non-New Zealand libraries.

\subsection{Perceptions of FLOSS options}

Rafiq (2009) carried out an in-depth qualitative study into the perceptions of FLOSS at libraries internationally, including 39 public libraries. It looked into the userfriendliness, functionality and quality of documentation. Rafiq found a wide range of perceptions, but they were generally positive towards FLOSS. There were no significant differences in opinions from public sector and private sector librarians, except with regard to functionality. The study found that private librarians were more likely to say that FLOSS provided lower functionality than commercial equivalents. There were significant differences in perceptions between respondents from developed countries and respondents from developing countries. The author doesn't discuss why this is, but it may be because licensing costs are more prohibitive than support, 
training and maintenance in many developing countries. Unfortunately the study didn't look into how realistic respondents' perceptions are.

Beatrice (2013) studied the use of FLOSS in a broad range of Kenyan libraries. The Kenya National Library was studied, which is the government-funded public library in Kenya and has branches in cities and towns across Kenya. However the study didn't break down the results relating to the Kenya National library. As most libraries surveyed were from educational institutions it is difficult to ascertain the use of FLOSS in Kenyan public libraries from this study. The study found that Kenyan librarians were strongly supportive of FLOSS options, and that FLOSS philosophies matched that of libraries.

Dalling and Rafferty (2013) studied perceptions to FLOSS ILSs in British educational libraries and found that librarians were reluctant to choose FLOSS options and were unlikely to use them in the future. Albee et al. (2014) looked at public library staff's perception to Evergreen, a FLOSS ILS. The study found the staff had very positive perceptions towards Evergreen.

\subsection{The ethos of the FLOSS movement and public libraries}

Several writers talked about the similarities between the ethos of the FLOSS movement and public libraries. Singh (2014, p52) pointed out they both depend on 'community effort' for their success and says this is why FLOSS is popular with librarians. Jaffe et al. (2007, p1) showed they had shared values of openness and accessibility.

Morgan (2001, p106-107) and Morgan (2000) wrote that both the FLOSS community and librarians believe that free information will improve society, and give away information and data without regard to fees or tangible exchanges. They both put a premium on open access, and operate as gift cultures so they gain reputation by the amount of intangible benefits they give away. 


\subsection{How FLOSS is being used in public libraries}

Rehman, Mahmood and Bhatti (2012) have completed a qualitative study into how FLOSS is used in Pakistani libraries. The study mainly focuses on educational libraries. Rehman et al. found that Koha, a FLOSS integrated library system (ILS), is widely used and has been adapted by librarians and developers for local use by adding Urdu spine label and MARC record export functionality.

Hanumappa, Dora and Navik (2014) have researched how FLOSS is being used in Indian libraries. The study surveyed 356 librarians, with three of those working in public libraries. The results were not broken down into types of libraries. They have found that only around 70\% of Indian libraries are using proprietary ILSs, with the majority of the remainder using Koha or Evergreen FLOSS ILSs. They have found the FLOSS ILSs to have features comparable to proprietary systems, and that large Indian libraries are converting to FLOSS solutions. In their satisfaction survey they found that Koha stood out with highly satisfied users.

Payne and Singh (2010) looked at which FLOSS libraries are using in a very general sense. Their paper is a good introduction to the topic.

Chen and Albee (2012) was one of the few studies of patrons' direct user experience of FLOSS, and focussed on how library patrons found using the FLOSS Evergreen ILS online public access catalogues (OPACs).

Beatrice (2013) found that few libraries were using FLOSS but many were switching their ILSs to Koha. Khode et al. (2015) surveyed the online OPACs of Indian libraries. The study found that of the libraries using FLOSS OPACS, 80\% were using Koha and $9 \%$ of them were public libraries. 
Lack, Ball, Kujenga, Chimuka, Mataranyika and Musemburi (2013) looked at how to increase library usage at Zimbabwean libraries through FLOSS solutions. These included accessibility tools for people with visual disabilities or reading difficulties. In these cases proprietary software wasn't a viable option, so the researchers concluded that the FLOSS solutions "changed lives".

Dugmore, Lindop and Jacob (2014) and Cutting (2014) talked about the Auckland Central Library makerspace, the goals of it, the issues with setting it up, and measuring its effectiveness. They briefly mention some of the FLOSS used in it and its importance to the makerspace.

Singh (2013) studied the experiences of librarians migrating to a FLOSS ILS. Most of the libraries looked at were public libraries and Singh discusses who makes the decisions and how they were made. Shafi-Ullah and Qutab (2012) provide an in-depth case study about libraries migrating to Koha and the issues they encountered.

\subsection{Libraries initiating FLOSS projects}

Ransom, Cormack and Blake (2009) produced a thorough account of the Horowhenua Library Trust's decision to commission developers to create the world's first FLOSS ILS, Koha. It clearly outlines how decisions were made and includes some analysis of decisions made that they later regretted. The library decided to use their own version of Koha rather than the main-line version for several years, which meant they were unable to upgrade. As the ability to customise software has come up several times in the literature as a benefit of FLOSS, it will be worth looking into whether or not customising FLOSS is a good idea, and whether or not it is a real benefit. Hadro (2009) covered the Horowhenua Trust's campaigning against the forking of the Koha codebase and trademark application by LibLime.

Ransom (2008) gives a similar account of the Horowhenua Library Trust's experience with developing the Kete system. Hall and Love (2012) talk about Te Reo o Taranaki 
Trust funding some of Kete's original development work and laments how the vision of collective resourcing of Kete's development never happened. They critique Kete's user interface for its low-level of intuitive design and the command-driven backend. They point out the lack of audio, privacy and security features makes it less than ideal for Māori communities.

Hall, Murdock Ames and Brice (2013) give a similar account of developing Libki, a FLOSS public computer access system for public libraries. This was originally created for the Crawford County Federated Library System, a rural American library that already had extensive use of FLOSS including Koha.

\subsection{Benefits and drawbacks of FLOSS}

A survey of librarians in India conducted by Hanumappa et al. (2014) found that the most frequently identified advantage of FLOSS was the cheaper cost. Chen et al. (2012), Payne and Singh (2010) and Singh (2013) also found the benefits were cheaper costs. Lack et al. (2013) pointed out the ability to install software on patron's laptops without being concerned about licensing restrictions was useful. However Dalling and Rafferty (2013) found the perception in British higher education libraries that FLOSS was more expensive due to higher installation costs.

Payne et al. (2010) and Rehman et al. (2012) found the ability for libraries to customise FLOSS was a significant benefit. Beatrice (2013) found strong agreement that FLOSS provided flexibility to customise for local needs. However many customisations of FLOSS can result in the library becoming unable to upgrade their software easily. Ransom et al. (2009) was the only article in this review to talk about these issues. Albee et al. (2014) found their FLOSS ILS had greater functionality than proprietary alternatives.

Hanumappa et al. (2014) found that the biggest barrier to FLOSS implementation was the lack of professional support. 


\subsection{Conclusions}

There appears to be a consensus across the literature that FLOSS solutions are perceived as more cost-effective than proprietary solutions. However none of the studies go into the costings to see if FLOSS truly is a more cost-effective option.

There is very little research on public access computers in public libraries, which often provide a great deal of FLOSS for public use. There was limited research on FLOSS use in New Zealand public libraries, and much of the international research was practitioner-based.

\section{Research design and methodology}

This research project is an instrumental case study of four institutions who are already using FLOSS. This approach will enhance understanding of the issues and give greater insights into the explanations underpinning the issues (Hancock \& Algozzine, 2011, p.37, 91). The following institutions are studied:

- The Auckland Libraries makerspaces, which are running a wide range of FLOSS within Auckland Libraries.

- Te Horowhenua Trust, which runs Horowhenua District's libraries and initiated the Koha and Kete projects.

- The Aotearoa People's Network Kaharoa (APNK), which provides public internet, computer access and other services to public libraries across New Zealand. Although they run the Microsoft Windows system, they provide FLOSS applications such as LibreOffice, Audacity, and GIMP.

- South Taranaki LibraryPlus, which uses Koha and has sponsored features in it (Cormack, 2011).

The study involved in-depth open-ended interviews with eight staff from APNK, Auckland Libraries makerspaces, Te Horowhenua Trust, and South Taranaki 
LibraryPlus. The interviews took place in person, on the telephone, and on Voice over IP (VOIP) software. Open-ended interviews allowed the interviewees to digress from the questions, offer opinions, and bring up related relevant material. To avoid confusion the interviewer used the term "open source software" rather than "FLOSS" or "free software", as often library staff confuse free software with proprietary software that can be obtained free of charge (such as Google Chrome).

Data was analysed using qualitative analysis, with themes and categories that came up in the interviews grouped together, to conclude underlying themes. A phenomenological study was used, which involved attempting to "understand people's perceptions, perspectives and understandings of a particular situation" (Leedy \& Ormrod, 2013, p.145).

\subsection{Ethical considerations}

The study was approved by the School of Information Management Human Ethics Committee (HEC) as it involved human participants. The study guaranteed informed consent as it could potentially have involved commercially sensitive information being supplied in confidence. The interviewees are not mentioned by name and their identities will remain anonymous.

\section{Findings}

All participants were happy with the FLOSS they were using and said they would choose FLOSS options in the future. Some participants said they couldn't see any drawbacks or problems with FLOSS.

\subsection{List of FLOSS being used in New Zealand public libraries}

The study found that the following FLOSS was being used in the four libraries surveyed: 
- Apache HTTP Server - the world's most widely used web server.

- Apache Tomcat - a web server extension.

- Arduino - software to run the open-hardware Arduino kits.

- Audacious - a lightweight audio player.

- Audacity - a digital audio editor application.

- Blender - a 3D animation program.

- Calibre - an e-book application suite that manages e-book collections and allows you to create e-books.

- CentOS - a Linux distribution.

- Cheese - webcam software.

- Chromium - the FLOSS counterpart to the Google Chrome web browser.

- Cura - preparation software for 3D printing.

- Ekiga - software for video-conferencing and VoIP (voice over the internet). Ekiga is similar to Skype.

- Firefox - a web browser.

- FluidSynth - an audio synthesizer.

- FontForge - font editing software.

- FreeBSD - an operating system that works in a similar way to Linux.

- Freemind - a mind-mapping tool.

- GIMP - a raster graphics editor.

- GNU Paint - a raster graphics editor.

- Hugin - photo stitching and high-dynamic-range (HDR) merging software.

- Hydrogen - a drum machine.

- Inkscape - a vector graphics editor.

- Kete - digital repository software for sharing online.

- Kino - a non-linear digital video editor.

- Koha - an ILS developed in New Zealand.

- LibreOffice - an office suite based on the OpenOffice suite.

- LilyPond - a program for engraving sheet music. 
- LMMS (Linux multimedia studio) - includes a synthesizer, a song editor, a beat maker, and an audio editor.

- Mixxx - DJ-ing and beat-matching software.

- MongoDB - a document database.

- MusE - a MIDI/Audio sequencer.

- MuseScore - a music score-writer.

- MySQL - a database management system.

- Notepad++ - a text editor and source code editor.

- NonVisual Desktop Access (NVDA) - screen reading software.

- OpenJDK - a FLOSS version of the Java platform.

- OpenOffice - an office suite including a word processor, a spreadsheet, a presentation application (similar to PowerPoint), a drawing application, a formula editor, and a database management system.

- OpenSCAD - software for creating 3D CAD objects.

- OpenShot - a video editor.

- PHP - an interpreter for running scripts on a web server written in the PHP scripting language.

- PiTiVi - a video editor.

- PostgreSQL - a database management system.

- Qtractor - digital audio recording software.

- Rapid Typing - a typing tutor.

- Raspbian - an operating system for Raspberry Pi single-board computers.

- Repetier Host - 3D printing software. The latest version isn't FLOSS.

- Ruby on Rails - a web application framework.

- Scribus - a desktop publishing application.

- SilverStripe - a content management system originally developed in New Zealand.

- Squid - a caching and forwarding web proxy. It is often used to speed up a web server.

- Stopmotion - a stop-motion animation movie creator. 
- Synfig - a 2D vector graphics and timeline-based animation program.

- Ubuntu Studio - a distribution of Linux that is geared towards multimedia production.

- VLC media player - used for playing audio and video.

- WinFF - a video converter.

- Wordpress - a content management system.

- Xara Xtreme - a vector graphics editor.

- Xwax - a vinyl record emulator.

\subsection{Te Horowhenua Trust}

Te Horowhenua Trust is a charitable trust that runs a network of four community libraries for the Horowhenua District Council. There is a central library in Levin and branches in Foxton, Shannon, and Tokomaru. The Levin library is called Te Takere and is promoted as a community hub and learning space. The trust's name was changed from the Horowhenua Library Trust to Te Horowhenua Trust in 2011.

The trust initiated and continues to use two major FLOSS projects; the Koha ILS in 1999, and the Kete digital repository in 2006. As well as Koha and Kete they use SilverStripe for their website, WordPress for their intranet, and Arduino, GIMP, and Raspbian in their children's technology workshops.

The district council was using the proprietary software EPiServer for their intranet but the library staff felt it had too many limitations, so they set up WordPress for the library intranet. One participant was very positive about WordPress, and the number of plug-ins available and said:

"You can add modules and plug-ins to do so many things - I don't know why you wouldn't use it. We have web forms for bookings, events calendars, contact directory - we have active directory set up. It just makes so much sense." The number of plug-ins available appears to be a direct result of WordPress being released under a FLOSS licence. 
One participant found SilverStripe difficult to learn with a confusing user interface. They said:

"The process to upgrade the core database is all command-driven server-side languages which are totally outside of my comfort zone. I found that a huge barrier."

Children's technology workshops at Te Takere often have a FLOSS theme, such as robot programming with Arduino, Graphics workshops with GIMP. They have just bought several Rapberry Pis running Raspbian. The participants were happy with all this software.

Te Takere are also running a studio and digital content creation suite with a fully functioning radio station. This uses one Mac and two Windows PCs. The staff chose to set this up with proprietary software because it is standard software for the audio industry.

\subsubsection{Koha}

In 1996 the Horowhenua District Council settled all the assets of the libraries except the buildings into the Horowhenua Library Trust. From this point onwards a culture of experimentation and innovation developed in the library (Ransom et al., 2009, p1). In 1999 the library needed to replace their outdated ILS partly because their networking system wouldn't handle the Y2K bug. When they searched for a replacement they found that replacement systems were either too expensive or only met some of their needs. All the existing systems had expensive communication solutions as none of them used the internet to communicate.

Therefore the trust decided to commission Katipo Communications, a Wellingtonbased web development company, to develop an ILS and release it with a FLOSS licence. The system was built on existing FLOSS; the Debian Linux operating system, the MySQL relational database management system, and a Perl compiler. 
Some of the reasons for releasing it with a FLOSS licence were to give the project longevity, and because an FLOSS library system was a "public good". The FLOSS ethos fitting well with the library ethos was brought up at meetings when the decision was being made (Horowhenua Library Trust, 1999). The decision was a risky one partly because of the family relationships between Katipo and the library. One participant said:

"Everyone said 'don't develop your own software that's stupid'.... The trust board are made up of people from the community that care about libraries but between them have a lot of business expertise, and they took a calculated business risk to go down this path. ... I remember talking to Rosalie Blake, the head of the libraries at the time, and saying 'are you sure you want to go down this way? After 30 years of an amazing professional career in libraries this is a really high risk venture for you to go down'. Because her son was the owner of the company and her daughter-in-law was going to work with the development. So high risk potentially if it all went wrong. She had already had this discussion with the trustees and the collective decision was 'if you can't trust your son to deliver for you.' These are the familial relationships whereby if someone lets you down they're going to have to live with that knowledge forever."

One participant said choosing Koha over a proprietary ILS had saved the council and the library over a million dollars over ten years.

Initially the library didn't participate in the community that built up around Koha and customised the system without upgrading from the "main trunk" of the project. This became a problem as initially Koha was built to handle bibliographic records in an arrangement that later became known as FRBR (functional requirements for bibliographic records). Each bibliographic record had a group of records attached for each edition of the title. This allowed patrons to request either a particular edition of a book or the first available edition. However the main trunk of Koha developed with the more traditional and less functional MARC (machine readable cataloguing) 
system. Horowhenua used their own version of Koha until 2005 when they installed the standard version; which by that stage had become a very different system. One participant thought the library should have done more to convince the Koha community of the benefits of Horowhenua's arrangement. They said:

"One of them was not staying with the main trunk of development. We had a version that we loved and we stayed with it. Instead of upgrading to keep with the main project, we became quite isolated. We didn't care about MARC at that point. Still don't really. But it was really important to the global community so they put MARC into it, and they broke our FRBR arrangement that was set up. That was so distressing to us that we just closed our eyes and carried on, and what we should have done was advocated more for it. We should have stuck with that principle. We should have articulated it better. We should have defended it more. And we didn't. So we got really out of step with the global community. We weren't reaping any of the benefits or the returns of being part of an open source project. We learnt from that. We're now back to that main trunk of development and we are committed to staying there. That does mean that you need to participate in discussions. Which is quite different - lots of libraries don't do that."

In 2011 LibLime managed to trademark the name Koha for their forked version of the software. Horowhenua Library Trust received donations from around the world for legal fees to fight the trademark decision, which was over-turned in 2013 (Grocott, 2013). One participant felt this was primarily a moral victory and said:

"They lost their trademark battle in New Zealand which was significant. The community was delighted. In a practical sense it won't have any impact on them at all. It was a moral victory. (LibLime) bled a lot of clients because people felt duped. They'd been tricked into buying open source, and the LibLime version is not." 
Participants said that a benefit of FLOSS was that they had more of an ability to determine future features and functionality, which they wouldn't have much say in with a proprietary system. The trust still sponsors features for it. A participant said:

"If I want add new functionality into Koha we can just contact Catalyst in Wellington and we'll pay them ten hours work. They can make it available for us and for anyone else to use. So we can be very responsive and we can get things done very quickly as well."

There was some concern that New Zealand librarians still saw Koha as an ILS for small library systems because it was originally developed for a small town. One participant said:

"Perhaps we're not good enough at shouting about how it's being used around the world. In the USA it's used by some massive consortia. New Zealand hasn't got the best value out of it yet but the potential is there for it."

\subsubsection{Kete}

Kete is a FLOSS online digital repository for heritage collections. Like Koha, it was developed by Katipo Communications with the Horowhenua Library Trust. The name, meaning basket, was chosen to echo the Māori proverb of the god of the forest and birds, Tāne, reaching up to the uppermost realm to retrieve three baskets of knowledge (Ransom, 2008, p4). The three baskets have been seen to represent current knowledge, the knowledge currently sought, and things unknown (Taonui, 2012).

The library trust had worked closely with historical societies and were keen to support them (Ransom, 2008, p2). The library's manager Joann Ransom said that Kete allows the community to transform the library (For the people, 2010). After setting up Kete Horowhenua APNK set up Kete installations for libraries around New Zealand. It has also been used for the Orlando Memory project in Florida, USA. One participant was pleased with Kete and said:

"Kete Horowhenua, which was incredibly popular and successful and our community love it, and to this day it's still a hugely important tool for us." 
However the software didn't develop the community of supporters that Koha did, so it has become out-dated. One participant said:

"It's an example of an open source project that hasn't really had wider support within the developer community so it doesn't get developed. As a result it's not a modern interface."

Another participant said the project had been forked in to a proprietary system. They said:

"Technically RabidTech has been doing development work for Kete but they are not releasing their work in to the public domain, and they are struggling to create a business model where they are able to generate revenue out of the development work they are doing."

Another participant explained that it would be unfair to release the source code of the updated Kete. They said:

"It never got the traction that Koha did. All of these libraries were given a free Kete not understanding that it's like a puppy. Sure you can have it for free but there's on-going costs to maintaining it, looking after it, caring for it, growing it, developing it. They never ever budgeted to contribute to it. We budgeted 10-20k a year to develop it. It's a really important tool for us. Libraries budget for library management systems but for some reason they never actually budgeted to contribute or support Kete. After 10 years of no development it became incredibly dated. There was a real security risk around the baseline Ruby on Rails foundation it was built on. I could not get other libraries to help fund the development work. Horowhenua has 30,000 people and we're quite poor, and it was just ridiculous that we were carrying the nation and no-one else was contributing. I had to make a choice, whether to develop it for all or just look after my rate-payers' assets because we couldn't get the funding. We've upgraded our installation of Kete but no-one else's. There's been a lot of conversations happening with DigitalNZ because the National Library has a 
legal responsibility to look after our heritage. National Library has not stepped up to the bar at all. Horowhenua ratepayers invested $\$ 50,000$ over three years to plug a security flaw, and my ratepayers stuff is now safe. Nobody else would help fund that work and it is completely unreasonable for Horowhenua ratepayers to carry the nation. ... We've paid to have it completely re-written in the last year."

\subsection{Aotearoa People's Network Kaharoa}

The Aotearoa People's Network Kaharoa (APNK) is partnership between the National Library of New Zealand and public libraries in New Zealand. It provides public internet and computer access to public libraries across New Zealand. It also hosts Kete digital repositories for public libraries, and hosts and supports the Kōtui shared library system.

On their back-end servers in their data centre run they run CentOS, Apache HTTP Server, Apache Tomcat, FreeBSD, MySQL, PostgreSQL, MongoDB, OpenJDK, PHP, Ruby on Rails, Squid and Kete. The participants were very happy with this software. One participant said:

"In terms of the server stuff, it really simplifies deployment of new servers so we don't have to worry about licensing a new CentOS server - it doesn't add to our costs at all. It gives us the freedom to deploy with an operating system without having to worry about those licence costs. Theoretically there are no additional charges as far as software licensing is concerned that need to be passed on to our customers or paid for by central government."

\subsubsection{Public access computers}

On their public access PCs for library patrons they provide Firefox, Audacity, Freemind, LibreOffice, Notepad++, NonVisual Desktop Access (NVDA), Rapid Typing, VLC media player and Calibre; along with proprietary software such as Microsoft 
Office and Internet Explorer. They all run on Microsoft Windows 7. Many patrons learn how to use and become familiar with computers in the library so the choice of software provided is important.

They decided to run Windows desktops instead of Linux primarily because the user interface is a business standard. One participant said:

"We wanted to provide people with the same experience in the libraries as they would expect to experience in the rest of their daily lives. Most people would not experience Linux on the desktop in any aspect of their life. If you think about a person going into work at a corporation; let's say they go to work at Vodafone or ASB bank; they would be presented with an operating system they would have to know how to navigate. We've tried to create that same environment for our customers."

One participant said their favourite FLOSS product was the screen-reading software NVDA, for which APNK won an Extra Touch Award from the Association of Blind Citizens of New Zealand for providing. They said:

"Without open source software some of the functionality we've been praised for wouldn't be there."

One participant was very pleased with GIMP and said:

"Having a fully-fledged image editor enables our customers to do something they wouldn't be able to do if there was no open source alternative. We could never afford 750 copies of Photoshop. So the fact that the software was free means that it becomes available to our customers."

They have recently switched from providing OpenOffice to LibreOffice, which they provide alongside Microsoft Office. LibreOffice is a fork of OpenOffice that currently has slightly more features. They both use the same document formats so can be used interchangeably. Providing a FLOSS alternative alongside Microsoft Office gives patrons a choice and means that when they go to buy their own computer they can 
have an office suite for free that they are familiar with. The participants were pleased with LibreOffice's functionality and said:

"Some of the tools that LibreOffice has you can't find in Microsoft Office, like

Office Draw which is quite a good drawing tool."

As APNK doesn't keep statistics on which software patrons are using we don't know which office suite is the most popular.

\subsubsection{Kōtui}

In 2011 the Kōtui board made the controversial decision to choose the proprietary SirsiDynix Symphony ILS over the FLOSS Koha ILS, when choosing a web-based ILS for small libraries in New Zealand (Pewhairangi, 2011). This issue wasn't discussed in interviews with APNK staff but some of the other participants who were using Koha brought up this issue. There were concerns around the decision-making process, and how FLOSS systems compete with proprietary systems in tender processes. The participants said:

"I've been very disappointed that at a national level they didn't look at open source when they did that consortia deal. It was a chance for people in powerful positions to stand up and say 'hey this is a very good way of us operating that meets the philosophy of being a librarian, about sharing and collaboration.' They chucked a whole bunch of money at a vendor. I think that's really sad."

"It's appalling. I find that absolutely shocking. And I think there was some skulduggery around that. I know there were three reviews done of that decision. The thing with open source is that you can't lie about it so when you get a questionnaire saying 'List the features' or 'does your software contain all of these features'; with Koha you have to be honest because anyone can download the code and have a look at it. That's not the same with other systems. They can say what they like. Over-promise and then under-deliver. That's what happened with Kōtui." 
"Any functionality that didn't exist at the time could be created very easily. Perhaps a lack of understanding of how Koha works and how the community works."

\subsection{South Taranaki LibraryPlus}

South Taranaki LibraryPlus is a network of seven library branches in Hawera, Patea, Waverley, Eltham, Manaia, Kaponga and Opunake. They use Koha and the APNK service.

They've been using Koha for four years and get support from Catalyst in Wellington. They decided on Koha because of the cost and the FLOSS philosophy.

They previously used the proprietary Liberty ILS and had difficulty with the software and the vendor. As it was proprietary they were locked in to getting support from one vendor. One participant said:

"With our last provider we ended up not getting along with the vendor. In the end we walked away because we weren't sufficiently important enough for them to do anything. .... Random stuff happened all the time. It got to the point where they weren't interested in helping us and were sick of us complaining. And they became utterly non-compliant and didn't return phone calls or emails."

The costs associated with Koha were significantly lower than comparable systems. One participant said:

"The cost of bigger systems for smaller libraries is excruciating. If you start to have problems with the vendor, small libraries don't have the power to make them toe the line."

They couldn't afford to sign up to Kōtui, a shared proprietary library system hosted by APNK. One participant said: 
"It's a huge amount of money, and we're stuck with what everyone's got whether it suits us or not. We would be paying 30 grand a year for the privilege of having something that doesn't suit you."

They found the FLOSS ethos to be in tune with the library ethos and appreciated the lack of vendor lock-in with FLOSS options. One participant said:

"We think it's a good philosophical fit for the library around sharing and being able to contribute back. We also didn't want to be locked into something where potentially a vendor could be bought out and you've no longer got support."

Both the staff and the patrons were very happy with Koha. One participant said: "We find Koha really good. We find it easy to use. We haven't had a single day where it doesn't work. We used to have quite a bit of downtime. So it means our patrons have a very consistent service. ... We've never had a down day. Staff love it."

South Taranaki LibraryPlus have sponsored a feature in Koha to retrieve the cover art of New Zealand books from the National Library catalogue. Currently most ILS systems only source cover art from Google and Amazon, both of which overlook most New Zealand children's books. They felt that sponsoring features was an important part of being part of the FLOSS community. One participant said:

"It means we can contribute back to the software as a whole. I think that's really important because when we look at what happened to Kete over the years, that's what went wrong. People didn't contribute back and it got outdated, which was a real shame."

South Taranaki LibraryPlus uses the APNK system for their public access computers. They hadn't noticed many patrons choosing the FLOSS options such as LibreOffice. Unlike other parts of the country their local Work and Income office gives specific instructions for clients to use Microsoft Word when creating CVs. 


\subsection{Auckland Libraries makerspaces}

Auckland Libraries run three makerspaces with PCs available to the public. They are at the Auckland Central Library, Panmure Library, and Te Matariki Clendon Library. They are setting up new makerspaces soon at Birkenhead, Waiheke Island, Avondale, Blockhouse Bay, and New Lynn. All the PCs use the Ubuntu Studio Linux distribution. The Central makerspace provides two 3D printers, and the Panmure and Clendon makerspaces have professional grade microphones. In 2014 they were nominated for a New Zealand Open Source Award.

They use the following music software: Audacious, Audacity, FluidSynth, Hydrogen, LilyPond, Mixxx, MusE, MuseScore, Xwax, Qtractor, and LMMS; and the following video software: PiTiVi, Kino, Stopmotion, WinFF, and OpenShot; and the following graphics software: Blender, FontForge, GIMP, Hugin, Inkscape, GNU Paint, Cheese, Scribus, Synfig, and Xara Xtreme. They also use OpenSCAD, Chromium and Ekiga. They use Cura and a FLOSS version of Repetier for their 3D printers.

Their reasons for choosing mostly FLOSS on their PCs was related to cost and ideology. Philosophically the makerspace is keen on levelling technologies. They were very keen for patrons to continue to use the software outside the makerspaces. Participants said:

"This kid comes in in South Auckland and says "Audacity is awesome, I have a computer at home, no internet, what do I do?" We can put it on a CD or a USB for them. If libraries are about access, accessing knowledge, and also accessing stuff; and here's a technology that is levelling. You don't have to pay for a licence. You don't have to get a pirated version."

"We also wanted to have the continuity to have the patron who might use some software on our computers and then go back home and perhaps download that software on their own computer at home."

Initially staff were hopeful that patrons would want to play with the source code and modify it but this hasn't happened yet. 
The 3D printing software is used heavily in the central library, while Audacity is used heavily in the Panmure library where patrons are using it for recording music.

\subsection{Relationship with IT departments}

A common theme in the interviews was the relationship with the IT departments of institutions' governing bodies, and how this affected their decision and ability to use FLOSS.

South Taranaki LibraryPlus use the South Taranaki District Council's IT department and say the IT department are very positive about FLOSS. One participant said:

"We've got a really good relationship with them. That's reasonably rare from what I hear. We've got a particularly forward thinking council; we're quite lucky. They're open to doing stuff differently. ... Philosophically our council is keen on open source software."

Longer term the council is interested in moving towards FLOSS products and getting away from Microsoft Office. The council was very happy with them sponsoring a feature in Koha.

APNK uses its own IT team and doesn't have to deal with the IT departments of the National Library of New Zealand and the Department of Internal Affairs. One participant said this makes it much easier to use FLOSS.

Because Te Horowhenua Trust is not a department of the Horowhenua District Council they have an unconventional relationship with the council's IT department. When Te Takere was being set up in 2012 the library's internal IT support team was transferred to the council IT department. The library now contracts the IT team to provide support but they don't need to ask for approval for anything from the council 
IT team. One participant doubted that Koha would have been initiated if the Horowhenua libraries had a more conventional relationship with their council.

Auckland Libraries uses their governing body Auckland Council's IT team, Information Services (IS). They also have one full-time technical support co-ordinator who works for the libraries. The makerspace doesn't deal with their council's IT department so library staff have to fix hardware and software issues themselves. The makerspace computers are completely separate from the council and library network. This was decided for reasons relating to flexibility. Participants said:

"We didn't ask IS early on because we didn't think it was important for them to be part of it."

"It was a big question what council IS was going to do when we've got open source computers that are off the grid."

"We wanted something that we could just change if we wanted to. We wanted to have people be able to download software on to our computers without the barriers that IS put up."

"As a body they (IS) are constrained by a particular ethos, one of which is that they want to have a secure system."

"That means we have to troubleshoot things ourselves and sometimes we aren't very good at that, but Google is our friend."

One participant felt that expecting an IT department to allow FLOSS was expecting too much of them, as IT departments have an ethos of protecting networks rather than being creative and opening access. They said:

"It's a completely different way of thinking. It's like asking someone to be a body builder and a gymnast at the same time. Why would you expect someone to do both? You would need different kinds of bodies. You would need different kinds of thinking. ... IT teams tend to be deeply conservative, extremely conservative people. Their job is to be conservative." 
They also saw the issue of IT departments not supporting computers with FLOSS in a positive light as it transformed the staff. They said:

"The beauty of the makerspace for the libraries; on the one hand it's the community stuff and helping people get access to technology, but it's also about us. It's about transforming us and transforming how we approach technology. Yes it will take a librarian a day to change a hard drive, but tomorrow one will take half a day; the next a quarter of a day; and ten hard drives down we have a service. It pushes us. It transforms us. The thing they say about giving to the poor, that giving to the poor does more for the person giving than it does for the poor. It transforms you."

A common thread in the interviews was the importance of being able to try out software on their computers. One participant said about trying out WordPress plugins, "I install it. See if it works. If it doesn't I swap it for another one." An Auckland Libraries participant said, "If I really want to do anything I go to the makerspace computers and do it." A participant from another institution said, "The idea that people would use a public computer to do their work is just madness." An Auckland Libraries participant said about not being able to install FLOSS on their councilcontrolled computers:

"It constrains our ability to work and our ability to try stuff out. ... I come from an institution where I was able to download simple programs and put them on my computer, so (not being able to) was kind of weird to me. I think we need a workforce that is able to experiment and try out new things. If people work in a culture where they can't experiment, then you really constrain innovation and the ability for people to come up with new solutions.... People try once and they get knocked back and they think 'it's not worth trying again so I won't bother. I won't bother innovating. I'll just sit at my desk and issue books." 


\subsection{Engaging with the FLOSS Community}

A common theme participants brought up was their engagement with the wider

FLOSS community, which can determine the success or failure of FLOSS usage. Te

Horowhenua talked about the issues they had when they hadn't joined in with the

Koha community effectively.

One participant was very pleased with how librarians worked with developers at Koha conference hackfests to brainstorm and refine ideas. They said:

"The consumer in there with the developer having a conversation face to face.

You couldn't do that with the owners of proprietary software. It's quite special."

Participants said about the Koha community:

"It's a really close community."

"There's a whole world out there of really clever people - libraries, vendors, and developers, who think of amazing things and we just cherry-pick the features that we want to turn on. It's pretty cool - you've got all these brilliant people out there working on it. We identify a few bugs every now and then."

Participants talking about the wider FLOSS community said:

"One of the key things for us is that the open source community help each other out and are open to collaboration. If we have problems we can go out to the community; there's someone online 24/7 and we've got an answer in minutes.

The time and angst you save is huge."

"When we first installed AV Linux I couldn't get the networking to work so I had to call a friend. The beauty of open source is that people are more willing to work with stuff than proprietary software."

"We've made quite a few friends just because we use Linux."

"There are generally supportive communities behind open source software who want to work with you to make it even better." 


\subsection{Attitudinal shift}

One participant said using FLOSS had changed attitudes of librarians and changed the way librarians thought.

\subsection{User interfaces}

Some participants reported that the file management system and user interface for Ubuntu Linux was difficult to use. They said the difficulties were only because staff and patrons were more familiar with Windows and Mac environments. One participant said, "It's not difficult; it's just learning a new thing. Learning a new thing takes time."

\subsection{Under-developed software}

One participant had a problem when they downloaded software from the Ubuntu Software Center without researching it or looking up reviews first. They found that not all the software's intended functionality had been completed yet. Unlike more restrictive software distribution platforms such as Apple's App Store and Google Play, software submitted to the FLOSS Ubuntu Software Center isn't reviewed by humans. The participant said:

"I went into it with a mind-set that 'software mostly works'. Sometimes Windows stuff crashes but the basic functionality usually works. I got half way into a little video project and found an audio function actually didn't go at all. This wasn't like a crash. This didn't work at all. You could slide the slider up and down and it just did nothing so it obviously wasn't connected at all."

\section{Conclusions}

Participants were generally positive about the FLOSS they were using, and were very positive about Koha. Problems with some software showed the importance of taking the time to research products before investing a great deal of time in them. Some of 
the issues were to do with user interfaces, but it is unknown whether this is a problem with FLOSS in general. Another problem with FLOSS can be customising software that is not then fed back into the main trunk of development. This can limit the ability to upgrade the software. FLOSS systems can become under-developed and obsolete, but there is no evidence that this more or less of a problem with proprietary software.

This study suggests that it is very important to share information about FLOSS across libraries so that money and staff time are not wasted on expensive solutions. It was interesting to note the Panmure Library and Te Takere were using very similar audiobased makerspaces. One was created very cheaply with FLOSS, and the other more expensively using industry-standard equipment. However this study did not directly compare the two makerspaces so we do not know which one was more effective for the patrons.

Reasons for deciding to use FLOSS matched with the reported benefits of using FLOSS. These include the lack of vendor lock-in, the cost, flexibility, ability to influence the development of the software, the philosophies and ethos of FLOSS, community support, and the ability to give patrons software to use outside the library. In many cases the FLOSS systems had better features and were more stable than the proprietary alternatives. Support for creativity and experimentation from governing bodies and IT departments was an important factor in the usage and success of FLOSS.

There is a lot of scope for further research in this area. Broader surveys of the use of FLOSS in New Zealand public libraries would be interesting, including a survey of the proportion of New Zealand libraries that use FLOSS ILSs, and how that compares to other countries. Another area for research is to investigate how software procurement decisions are made in libraries, and whether FLOSS is being overlooked due to preconceptions or uneven decision-making processes. 


\section{Bibliography}

Albee, B., \& Chen, H. (2014). Public library staff's perceived value and satisfaction of an open source library system. The Electronic Library, 32(3), 390-402.

Aotearoa People's Network Kaharoa. (2014). About Us. Retrieved August 18, 2014 from http://www.aotearoapeoplesnetwork.org/content/about-us

Barniskis, S. C. (2014). Makerspaces and Teaching Artists. Teaching Artist Journal 12(1), 6-14.

Beatrice, A. A. (2013). Feasibility of adaptation of open source ILS for libraries in Kenya: a practical evaluation. The Electronic Library, 31(5), 608-634.

Blake, R., \& Hamilton-Williams, R. (2000). Koha: free library software. Library life, 247, 20-22.

Breeding, M. (2015) Library System Report 2015: Operationalizing innovation. American Libraries, 46(5), 28-41.

Chawner, B. (2004). Free/open source software: new opportunities, new challenges.

Paper presented at the 12th VALA Biennial Conference: Breaking boundaries:

Integration \& Interoperability. Available from:

www.vala.org.au/vala2004/2004pdfs/33chawn.pdf

Chawner, B. (2005). F/OSS in the Library World: An Exploration. 5-WOSSE

Proceedings of the fifth workshop on Open source software engineering, 14-17.

Retrieved from the University of California - Irvine

http://www.ics.uci.edu/ wscacchi/Papers/WOSSE-2005/Chawner.pdf 
Chen, H., \& Albee, A. (2012). An open source library system and public library users: Finding and using library collections. Library \& Information Science Research, 34, 220-227.

Choi, N., \& Pruett, J. A. (2015). The characteristics and motivations of library open source software developers: An empirical study. Library \& Information Science Research, 37, 109-117.

Cormack, C. (2011). Koha 3.6.0 released. Retrieved January 23, 2015 from http://kohacommunity.org/koha-3-6-0-released/

Cutting, J. (2014). Makerspaces in libraries: A case study of the makerspace at Auckland Libraries. Unpublished report in partial fulfilment of Open Polytechnic Bachelor of Information Studies.

Dalling, J., \& Rafferty P. (2013) Open source, open minds?: An investigation into attitudes towards open source library management systems in UK higher education libraries, Program: Electronic library and information systems 47(4), 399-423.

Deek, F. P., \& McHugh, J. A. M. (2008). Open source: technology and policy. Cambridge, NY: Cambridge University Press.

Dugmore, P., Lindop, H. \& Jacob, B. (2014). Making the makers: an exploration of a makerspace in a city library. Paper presented at the LIANZA Conference 2014. Retrieved January 23, 2015 from http://www.lianza.org.nz/sites/default/files/Dugmore P Making the makers.pdf

Engard, N. C. (2010). Practical open source software for libraries. Oxford, England: Chandos Publishing. 
Feller, J. (2005). Perspectives on free and open source software. Cambridge, MA: MIT Press.

For the people (2010). Library Journal, 135(5), 43.

Free Software Foundation, (2013). What is free software? The Free Software Definition. Retrieved August 18, 2014 from https://gnu.org/philosophy/free-sw.html

Grocott, M. (2011). Libraries trust wins battle over trademark. Retrieved June 1, 2015 from http://www.stuff.co.nz/business/industries/9518019/Libraries-trust-wins-battleover-trademark

Hadro, J. (2009). LibLime's Enterprise Koha sets off debate. Library Journal, 134(17), 16-17

Hall, C., \& Love, H. (2012) Ka Puta, Ka Ora: Digital archiving and the revitalisation of Taranaki Reo. Archifacts, October 2011 - April 2012, 25-34.

Hall, K., Murdock Ames, C., \& Brice, J. (2013). Open Source Library Software Development in a Small Rural Library System. Code4lib Journal, (19), 1-10.

Hancock, D., \& Algozzine, R. (2011). Doing case study research. New York, NY, USA: Teachers College Press.

Hanumappa, A., Dora, M., \& Navik, V. (2014). Open source software solutions in Indian libraries. Library Hi Tech, 32(3), 409-422.

Horowhenua Library Trust. (1999). Minutes of the Horowhenua Library Trust Special Meeting held in the Library on Thursday 14 October 1999. Retrieved May 13, 2015 from: http://kete.library.org.nz/documents/0000/0000/0208/1999 10 27.pdf 
Houser, J. (2009). Open source public workstations: open source software lowers libraries' cost, environmental impact. American Libraries, 40(5), 35.

Jaffe, L. D., \& Careaga, G. (2007). Standing Up for Open Source. Library Philosophy and Practice, 9(2), 21.

Khode, S., \& Chandel, S. (2015). Adoption of Open Source Software in India. DESIDOC Journal of Library \& Information Technology, 35(1).

Lack, R., Ball, S., Kujenga, A., Chimuka, Y., Mataranyika, T., \& Musemburi, D. (2013). Increasing library usage through free open source software (FOSS) solutions: two case studies from Zimbabwe. Journal of Library Innovation, 4(2), 42-53.

Leedy, P. D., \& Ormrod, J. E. (2013). Practical research: planning and design (International edition; 10th ed.). Boston, MA, USA: Pearson Education.

$\mathrm{Li}, \mathrm{A}$. (2008). Investigation of ILS in Chinese main academic libraries. Library Collections, Acquisitions, and Technical Services, 32(3-4), 115- 120.

Morgan, E. (2000). Gift cultures, librarianship, and open source software development. Retrieved June 23, 2015 from http://www.infomotions.com/musings/gift-cultures/

Morgan, E. (2001). The Cathedral \& the Bazaar: Musings on Linux and Open Source by an Accidental Revolutionary. Sebastopol, CA, USA: O'Reilly Media.

New Zealand Open Source Awards. (2014). Award categories. Retrieved January 23, 2015 from http://www.nzosa.org.nz/categories

Open Source Initiative. (2014). The Open Source Definition. Retrieved August 18, 2014 from http://opensource.org/osd 
Payne, A., \& Singh, V. (2010). Open source software use in libraries. Library Review, 59(9), 708-717.

Pewhairangi, S. (2011). Kotui: An Update From Sue Sutherland Regarding Koha.

Retrieved June 11, 2015 from http://findingheroes.co.nz/2011/05/17/kotui-an-updatefrom-sue-sutherland-regarding-kohal

Primary Research Group (2013). The survey of library use of open source software. New York, NY, USA : Primary Research Group.

Pruett, J., \& Choi, N. (2013). A comparison between select open source and proprietary integrated library systems, Library Hi Tech, 31(3), 435 - 454.

Rafiq, M. (2009). LIS community's perceptions towards open source software adoption in libraries. The International Information \& Library Review, 41(3), 137-145.

Ransom, J. (2008). Kete Horowhenua: the story of the District as told by its people. Paper presented at the VALA conference, 5-7 February 2008. Retrieved May 23, 2015 from http://vala.org.au/direct-download/vala2008-proceedings/164-vala2008-session-4ransom-paper/file

Ransom, J., Cormack, C., \& Blake, R. (2009). How Hard Can It Be? : Developing in Open Source. The Code4Lib Journal, 7 (June 26, 2009). Retrieved from http://journal.code4lib.org/articles/1638

Rehman, A. U., Mahmood, K., \& Bhatti, R. (2012, July). Free and Open Source Software movement in LIS Profession in Pakistan. Library Philosophy and Practice, 119 .

Shafi-Ullah, F., \& Qutab, S. (2012). From LAMP to koha: Case study of the pakistan legislative assembly libraries. Program, 46(1), 43-55. 
Singh, V. (2013). Experiences of migrating to an open-source integrated library system. Information Technology and Libraries, 32(1), 36-53.

Singh, V. (2014). Open Source Software Use in Libraries: Implications for Social Justice? Qualitative and Quantitative Methods in Libraries, Special Issue 2014 Social Justice, Social Inclusion, 49-57.

Skidmore, D. (2007). FLOSS Legal and Engineering Terms and a License Taxonomy. In Handbook of Research on Open Source Software: Technological, Economic, and Social Perspectives. (pp. 394-410). Hershey, PA: Information Science Reference.

Stallman, R. (2010). Free software, free society: selected essays of Richard Stallman. Boston, MA : Free Software Foundation.

Taonui, R. (2012). Ranginui - the sky - Ranginui as knowledge and life. In Te Ara - the Encyclopedia of New Zealand. Retrieved June 23, 2015 from:

http://www.TeAra.govt.nz/en/ranginui-the-sky/page-2

Word count: 10326 